\title{
The Cannabinoid Receptor CB1 Stabilizes Sperm Chromatin Condensation Status During Epididymal Transit by Promoting Disulphide Bond Formation
}

\author{
Teresa Chioccarelli ${ }^{1}$ [D, Francesco Manfrevola ${ }^{1}$, Veronica Porreca ${ }^{1}$, Silvia Fasano ${ }^{1}$, \\ Lucia Altucci ${ }^{2}{ }^{-1}$, Riccardo Pierantoni ${ }^{1}{ }^{(1)}$ and Gilda Cobellis ${ }^{1, *(1)}$ \\ 1 Department of Experimental Medicine, Sez. Bottazzi, Università degli Studi della Campania "L. Vanvitelli", \\ Via Costantinopoli 16, 80138 Napoli, Italy; teresa.chioccarelli@unicampania.it (T.C.); \\ francesco.manfrevola@unicampania.it (F.M.); veronica.porreca@unicampania.it (V.P.); \\ silvia.fasano@unicampania.it (S.F.); riccardo.pierantoni@unicampania.it (R.P.) \\ 2 Department of Precision Medicine, Università degli Studi della Campania "L. Vanvitelli", Via L. De Crecchio \\ 7, 80138 Napoli, Italy; lucia.altucci@unicampania.it \\ * Correspondence: gilda.cobellis@unicampania.it; Tel.: +39-081-5667-528; Fax: +39-081-5667-536
}

Received: 5 March 2020; Accepted: 24 April 2020; Published: 28 April 2020

check for updates

\begin{abstract}
The cannabinoid receptor CB1 regulates differentiation of spermatids. We recently characterized spermatozoa from caput epididymis of CB1-knock-out mice and identified a considerable number of sperm cells with chromatin abnormality such as elevated histone content and poorly condensed chromatin. In this paper, we extended our findings and studied the role of CB1 in the epididymal phase of chromatin condensation of spermatozoa by analysis of spermatozoa from caput and cauda epididymis of wild-type and CB1-knock-out mouse in both a homozygous or heterozygous condition. Furthermore, we studied the impact of CB1-gene deletion on histone displacement mechanism by taking into account the hyperacetylation of histone $\mathrm{H} 4$ and players of displacement such as Chromodomain Y Like protein (CDYL) and Bromodomain testis-specific protein (BRDT). Our results show that CB1, via local and/or endocrine cell-to-cell signaling, modulates chromatin remodeling mechanisms that orchestrate a nuclear condensation extent of mature spermatozoa. We show that CB1-gene deletion affects the epididymal phase of chromatin condensation by interfering with inter-/intra-protamine disulphide bridges formation, and deranges the efficiency of histone removal by reducing the hyper-acetylation of histone $\mathrm{H} 4$. This effect is independent by gene expression of $C d y l$ and $B r d t$ mRNA. Our results reveal a novel and important role for CB1 in sperm chromatin condensation mechanisms.
\end{abstract}

Keywords: estrogens and endocannabinoids; caput and cauda epididymis; type-1 cannabinoid receptor (CB1); sperm chromatin condensation and maturation; protamine thiol oxidation; chromatin remodeling and histone displacement; spermiogenesis; post-translational modification of histone $\mathrm{H} 4$ (histone $\mathrm{H} 4$ acetylation); chromodomain protein CDYL; bromodomain protein BRDT

\section{Introduction}

Spermiogenesis is the terminal differentiation phase of spermatogenesis by which round spermatids (SPTs) undergo impressive histomorphological changes that facilitate development of mature and elongated cells carrying tightly condensed chromatin and nuclei, namely mature SPTs or spermatozoa (SPZs). When spermiogenesis completes, spermiation promotes detachment of SPZs from Sertoli cells. Downstream, a contractile tubular propulsion leads SPZs from tubular lumen-to-rete testis until caput region of epididymis. Sperm maturation occurs during epididymal transit from the caput-to-cauda region [1]. 
Chromatin condensation extent of mature SPZs is orchestrated by testicular and epididymal events. These require chromatin remodeling mechanisms such as histone displacement/protamination and inter/intra-protamine disulphide bonds formation, respectively [2]. In developing germ cells, nuclear condensation is mainly related to i) haploid expression of transition proteins (TNP1 and TNP2) and protamines, ii) histone post-translational modifications (PTMs) and displacement, and iii) histone-to-protamine exchange and DNA packaging [3-6]. The combined histone $\mathrm{H} 4$ acetylation at lysine $(\mathrm{K})$ residues $\mathrm{K} 5, \mathrm{~K} 8, \mathrm{~K} 12$, and $\mathrm{K} 16$ results in the main signal of global histone removal as the Bromodomain testis-specific protein (BRDT) reads and binds acetyl lysine eliciting histone displacement [7]. Additional histone PTMs are involved in this process [8]. The histone crotonylation is a new histone PTMs recently characterized in mouse germ cells [9,10]. A significant histone hyper-crotonylation has been described in elongating SPTs. This is responsive to down-regulation of Chromodomain Y Like protein (CDYL) and it has been related to histone removal. CDYL is a chromodomain protein that regulates negatively histone lysine crotonylayion (Kcr) because of its activity on crotonyl donor as crotonyl-CoA hydratase [10]. CDYL activity counteracts the acetyl-lysine reader BRDT since recent studies suggest that most bromodomains do not read cronyl-lysine [11,12]. In the Cdyl transgenic mouse model, the overexpression of CDYL decreases histone Kcr in elongating SPTs and interferes with histone displacement, which reveals a key role of CDYL in spermiogenesis as a modulator of histone PTMs with functional implications in histone removal mechanism [10].

In mammals, histone displacement preserves a small percentage of chromatin condensed by histones ( $2 \%-5 \%$ in mouse, $10 \%-15 \%$ in human) so that SPZs contain nucleoprotamines and a small fraction of nucleohistone chromatin [13,14]. Any interference with histone displacement in SPTs interferes with histone/protamine content and chromatin condensation of SPZs.

Protamines are sperm-specific nuclear proteins with high DNA affinity, as these are small and highly-basic proteins with an arginine-rich core. In eutherian mammals, including mouse and human, protamines are characterized by an arginine and cysteine residues [15]. During spermiogenesis, arginine residues mediate formation of highly stable DNA-protamine complexes that strongly condense chromatin in the toroidal structures [16]. During post-testicular maturation, cysteine residues close chromatin in tighter arrangement of protamines organizing toroids.

During epididymal transit, from caput-to-cauda, SPZs acquire their potential to move [17] and further condense chromatin through intra-/inter-protamine disulphide bonds [18] useful to stabilize and strongly condense DNA. Protamines have been recently proposed to be involved in imprinting and epigenetic regulation of sperm cells $[15,19,20]$.

Signals and pathways involved in physiologic sperm thiol oxidation in the epididymis are not completely understood. However, inter-/intra-protamine disulphide bridges formation is a crucial step, as this strongly condense nuclei of SPZ in a functionally and completely mature state that preserves genome integrity. The highly condensed chromatin masks the DNA from stressing agents, while uncondensed chromatin is mainly associated with DNA damage [21].

All the events previously described are finely regulated by neuroendocrine axis and local factors that act through endocrine, autocrine, and paracrine pathways [2,22]. Among factors, endocannabinoids have an emerging role because of their activity at hypothalamic, testicular, and epididymal level [22].

Endocannabinoids are cell-to-cell signaling mediators able to bind the cannabinoid receptor type- 1 and type-2 (CB1 and CB2) which are highly expressed in testis. Anandamide (AEA) and 2-arachidonoylglycerol (2-AG) are the main endocannabinoids characterized in testis and epididymis with a key role in spermatogenesis and sperm motility acquisition, respectively [22-24]. CB1 has been related to somatic and germ cell activities [24-35] and, in particular, to Leydig cell differentiation [30], steroidogenesis [25,35-37], spermiogenesis [2,38], quality, and epididymal maturation of SPZs [24,27-29,33,34,39,40].

Recent information about CB1 involvement in spermiogenesis came from male mice carrying a CB1-null deletion, either under heterozygous $\left(\mathrm{CB} 1^{+-}\right)$or homozygous conditions $\left(\mathrm{CB}^{-/-}\right)[33,41]$. The $\mathrm{CB1}^{-/}$mice show down regulation of hypothalamus-pituitary-gonad axis with low plasma levels of testosterone and $17 \beta$-Estradiol $\left(\mathrm{E}_{2}\right)[25,33,38]$. These animals produce SPZs with mature and 
immature chromatin (condensed and uncondensed, respectively) because of heterogeneous histone content $[2,33,38]$, likely ascribed to inefficient histone removal during spermiogenesis.

We recently characterized SPZs from caput epididymis of $\mathrm{CB}^{-/-}$mice and identified a considerable number of SPZs with a chromatin abnormality such as elevated histone content, poorly condensed chromatin, highly damaged DNA, and elongated nuclear size $[2,33,34,38]$. We showed that all these abnormalities were correlated to each other and responsive to down-regulation of neuroendocrine axis supporting gonadotropin- $\mathrm{E}_{2}$ production since $\mathrm{E}_{2}$-treated $\mathrm{CB} 1^{-/}$mice restored the number of SPZs with chromatin abnormalities to physiological values, which suggests the hypothesis that sperm chromatin quality was responsive to neuroendocrine activity of $\mathrm{CB} 1$ via $\mathrm{E}_{2}$-mediated mechanism [33,34]. Sperm chromatin of $\mathrm{CB}^{+/-}$mice appeared more similar to WT than $\mathrm{CB}^{-/-}$mice.

In this study, we extended our findings and analyzed the regulatory activity of CB1 in epididymal phase of sperm chromatin condensation. In particular, using wild-type $\left(\mathrm{CB} 1^{+/+}\right.$or WT) and CB1-deleted mice, both in a homozygous and condition, we studied sperm chromatin condensation status during the epididymal transit, by comparative analysis of SPZs from caput and cauda epididymis. Furthermore, we characterized a deficit of intra-testicular $\mathrm{E}_{2}$ levels and signal associated to inefficient histone displacement in $\mathrm{CB}^{-/}$mice.

\section{Results}

\subsection{Effects of CB1 Deletion on Sperm Chromatin Condensation During the Epididymal Transit}

Sperm samples from caput and cauda epididymis of $\mathrm{WT}, \mathrm{CB} 1^{+-}$and $\mathrm{CB} 1^{--}$mice were stained with Acridine Orange (AO) dye in acid conditions and comparatively analyzed by flow cytometry. The percentage of SPZs with high DNA stainability (i.e., HDS) or susceptibility of DNA to acid denaturation at strand break (i.e., DD), and thiol/disulphide status (i.e., TDS) were evaluated and used as spermatic indices of uncondensed chromatin, DNA denaturation and damage, and thiol groups oxidation status, respectively. All the HDS and TDS values, independently by genotype and epididymal region, were used for correlation analysis.

Figure 1A shows histograms of green- (FL1-H) and red- (FL3-H) stained caput and cauda SPZs from $\mathrm{WT}, \mathrm{CB}^{+/-}$, and $\mathrm{CB}^{---}$mice in the gated areas (M1 and M2).

Figure 1 shows the relative HDS and DD values (panel B and C) while Figure 2 show the relative TDS values (panel A) and correlation analysis between HDS and TDS values (panel B).

Sperm samples from caput and cauda epididymis of WT and CB1 $1^{+-}$mice showed scanty and comparable HDS values with no significant differences caput vs. cauda (Figure 1B). Sperm samples from caput and cauda epididymis of $\mathrm{CB}^{-/-}$mice showed HDS values significantly higher compared to WT and $\mathrm{CB}^{+/-}(p<0.01)$, both in caput and cauda epididymis with a significant increase, caput-to-cauda $(p<0.05)$.

Both in caput and cauda epididymis, sperm cells showed DD values significantly higher in CB1 ${ }^{--}$ mice than in WT and $\mathrm{CB}^{+/-}(p<0.01)$ (Figure $\left.1 \mathrm{C}\right)$. However, in $\mathrm{WT}$ and $\mathrm{CB} 1^{+/-}, \mathrm{SPZs}$ showed DD values higher in caput than in cauda epididymis $(p<0.01)$, while, in $\mathrm{CB}^{-/-}$mice, SPZs showed comparable DD values in caput and cauda epididymis.

In WT and CB1 ${ }^{+/}$, SPZs showed TDS values significantly higher in caput than in cauda epididymis $(p<0.01)$, while in $\mathrm{CB1}^{-/}$mice, SPZs showed TDS values with no significant difference caput vs. cauda (Figure 2A). In caput epididymis, SPZs showed TDS values significantly higher in $\mathrm{CB} 1^{+/-}$mice when compared to WT $(p<0.01)$ with a further significant increase in $\mathrm{CB}^{-/-}$mice $(p<0.01)$. In cauda epididymis, SPZs showed scanty and comparable TDS values in WT and CB1 ${ }^{+/-}$mice, and higher TDS values in $\mathrm{CB}^{-/}$mice compared to $\mathrm{WT}$ and $\mathrm{CB} 1^{+/-}$mice $(p<0.01)$. 
A)
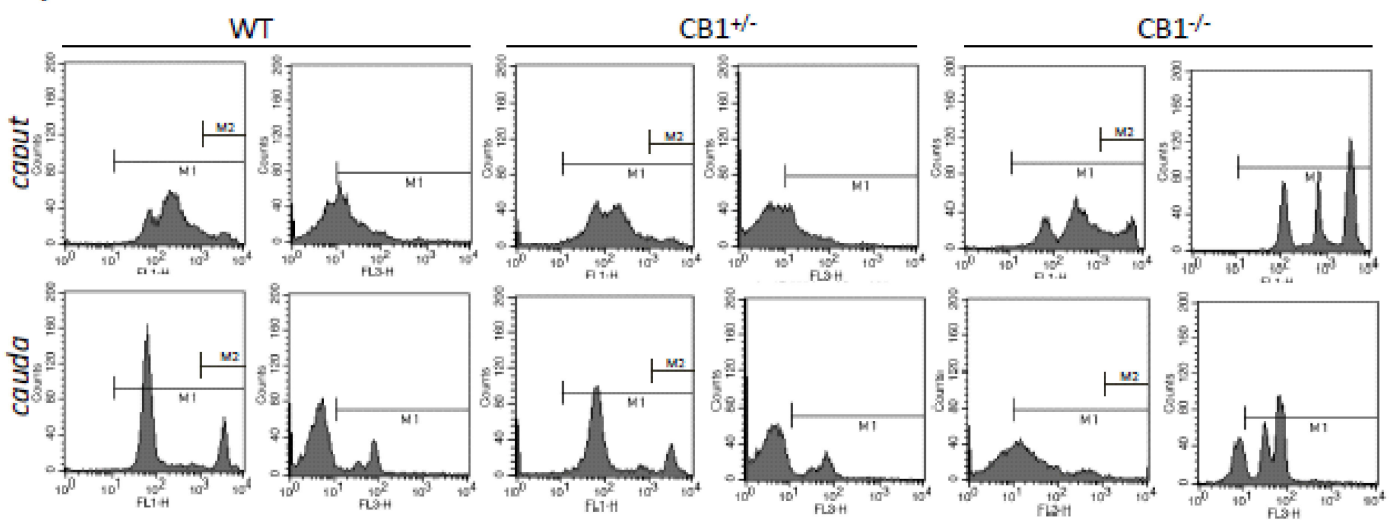

B)

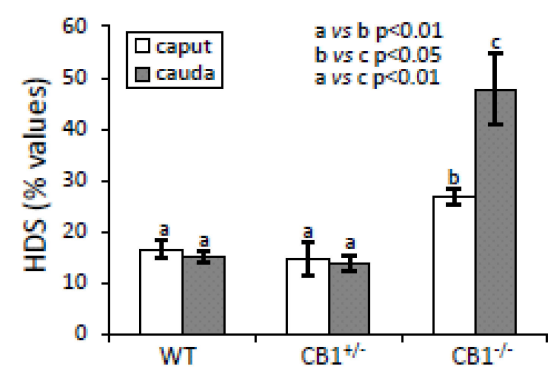

C)

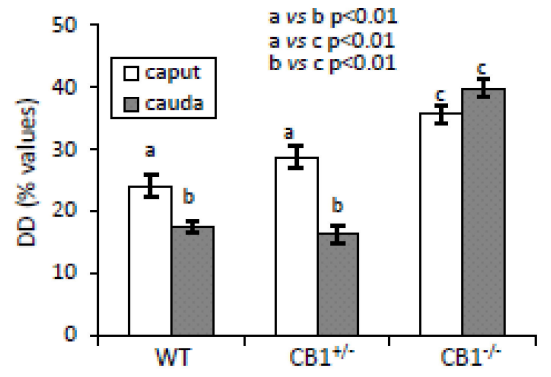

Figure 1. Flow cytometry analysis of sperm from caput and cauda epididymis of $\mathrm{WT}, \mathrm{CB} 1^{+/-}$, and $\mathrm{CB} 1^{-/-}$ stained with AO. (A) Representative histograms of AO stained sperm in M1and M2 gate. Intensely green $\left(\right.$ FL1-H $>10^{3}$ ), green $\left(\right.$ FL1-H $\left.>10^{1}\right)$, red $\left(\right.$ FL3-H $>10^{1}$ ) and total (green + red) fluorescencing DNA were used to analyze: (B) HDS (used as index of uncondensed chromatin) and (C) DD (used as index of DNA damage) values. Graphs were representative of four sperm samples/animal/genotype $(n=4$ animals for each genotype in triplicates). Data were expressed as the mean values \pm S.E.M. Different letters indicated statistical significance $(p<0.05$ or $p<0.01)$.

A)

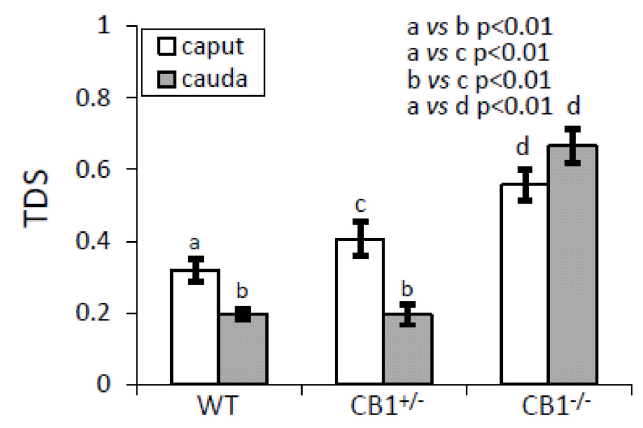

B)

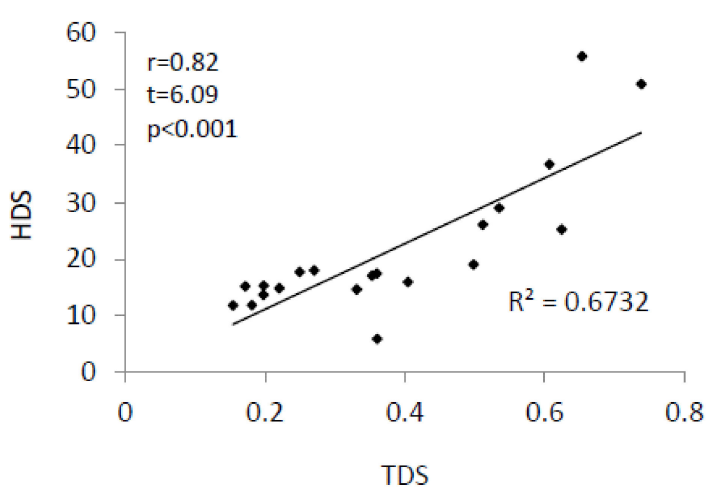

Figure 2. Flow cytometry analysis of sperm from caput and cauda epididymis of WT, CB1 ${ }^{+/}$, and $\mathrm{CB}^{-/}$-stained with $\mathrm{AO}$. Green $\left(\mathrm{FL} 1-\mathrm{H}>10^{1}\right)$ and red $\left(\mathrm{FL} 3-\mathrm{H}>10^{1}\right)$ fluorescent DNA were used to analyze: (A) TDS (used as index of thiol groups oxidation) values. Graphs were representative of four sperm samples/animal/genotype ( $n=4$ animals for each genotype in triplicates). Data were expressed as the mean \pm S.E.M. Different letters indicated statistical significance $(p<0.05$ or $p<0.01)$. (B) Correlation analysis between HDS and TDS values relative to caput and cauda SPZ of WT, CB1 $1^{+/-}$ and $\mathrm{CB}^{-/}$, independently by genotype and epididymal region $(r=0.82, p<0.001)$. 
Correlation analysis shows that HDS and TDS values are positively $(r=0.82)$ and significantly $(p<0.01)$ correlated with each other (Figure 2B).

\subsection{Impact of CB1-Gene Deletion on Chromatin Condensation of Efficiently Protamined CB1-Null SPZs During the Epididymal Transit}

$E_{2}$ treatment was used as an experimental approach to recover sperm protamination efficiency in CB1-null mice. This experimental approach was useful to study the impact of CB1-gene deletion on sperm protamine thiol group oxidation during the epididymal transit by avoiding interference by poor protamination.

$\mathrm{CB}^{-/-}$mice were treated with vehicle or $\mathrm{E}_{2} \pm \mathrm{ICI}$ and analyzed in comparison to WT mice, which are used as a control reference in this case. Efficiency of histone displacement was used as an experimental control of $E_{2}$-treatment efficacy and evaluated by analysis of testicular content of histone H3. Spermatozoa collected from caput and cauda epididymis were used to analyze the chromatin condensation status via HDS and TDS indices.

Histone H3 (Figure 3A) was present in testis, independently by genotype or treatment (upper panel). Quantitative densitometry analysis of signals (lower panel) showed that histone H3 levels were significantly lower in $\mathrm{E}_{2}$-treated $\mathrm{CB}^{-/}$mice in comparison to other experimental groups $(p<0.05)$. No significant difference between Control (CTRL) vs. $E_{2}+$ ICI was observed. $E_{2}$-treatment restored histone $\mathrm{H} 3$ levels to WT values. This rescue activity demonstrated the efficiency of $\mathrm{E}_{2}$ treatment and confirmed that $\mathrm{E}_{2}$-treated $\mathrm{CB}^{-/}$mice release in caput epididymis efficiently protamined SPZs because of histone displacement recovery [38].

Figure 3B show HDS values. In WT mice, SPZs showed scanty and comparable HDS values in both caput and cauda epididymis. In all the experimental groups, SPZs showed HDS values significantly lower in caput than in cauda epididymis $(p<0.01)$ with comparable values in cauda. Comparatively to CTRL or $\mathrm{E}_{2}+$ ICI groups, $\mathrm{E}_{2}$-treatment significantly reduced HDS values in caput epididymis $(p<0.01)$, which confirms efficiency of $E_{2}$ treatment [33]. In WT mice and $E_{2}$ treated animals, caput SPZs showed similar HDS values.

Figure 3C show TDS values. In WT mice, SPZs showed TDS values higher in caput than in cauda epididymis $(p<0.01)$. In all the experimental groups, SPZs showed comparable TDS values in both caput and cauda epididymis. Comparatively to CTRL or $\mathrm{E}_{2}+\mathrm{ICI}$ groups, $\mathrm{E}_{2}$ treatment significantly reduced sperm TDS values both in caput and cauda epididymis $(p<0.01)$. In caput epididymis, SPZs showed similar TDS values in WT and $\mathrm{E}_{2}$-treated animals. 

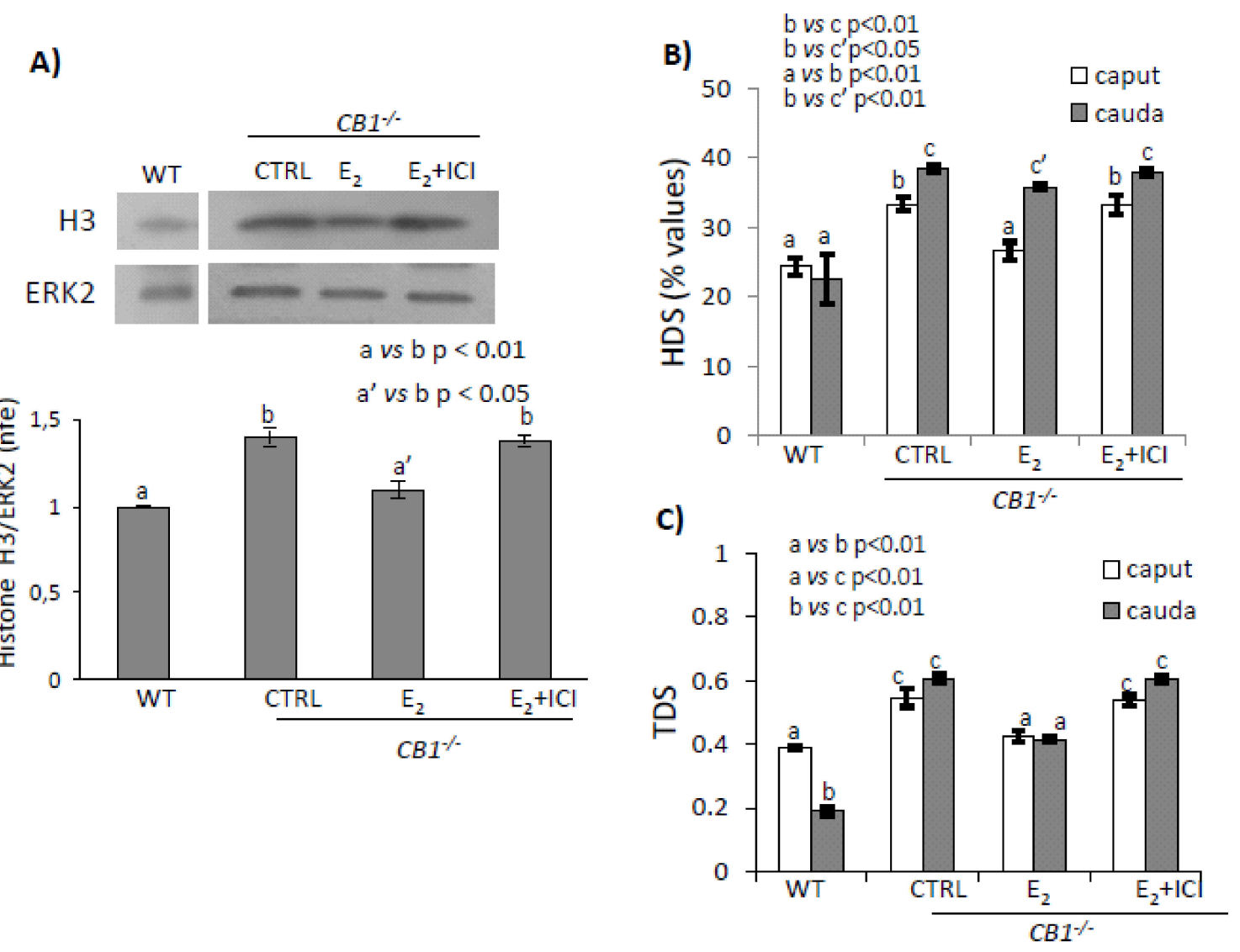

Figure 3. (A) Western blot analysis of Histone $\mathrm{H} 3$ in testis from $\mathrm{WT}$ and $\mathrm{CB} 1^{-/}$mice in vivo treated with vehicle (CTRL) or $\mathrm{E}_{2} \pm$ ICI. $\mathrm{H} 3$ amount was quantified by densitometry analysis, normalized against ERK2 signals, and expressed as a fold change of OD values. Graphs were representative of or four testis/experimental group ( $n=3$ or 4 testes from different animals for each experimental group in triplicates). Flow cytometry analysis of caput and cauda SPZ of CB1 $1^{-/}$mice in vivo treated with vehicle (CTRL) or $\mathrm{E}_{2} \pm$ ICI. (B) HDS (used as index of uncondensed chromatin) and (C) TDS (used as index of thiol groups oxidation) values. Graphs were representative of three or four sperm samples/animals/experimental groups ( $n=3$ or 4 animals for each experimental group in triplicates). All data are reported as mean values \pm S.E.M. Different letters indicated statistical significance $(p<0.05$ or $p<0.01, \mathrm{a}^{\prime}$ vs. a: not significant).

\subsection{Characterization of Intra-testicular $E_{2}$ Deficit and Histone PTMs Associated to Inefficient Histone Displacement in $\mathrm{CB1}^{--}$Mice}

Using WT and $\mathrm{CB}^{-/}{ }^{-}$mice, we verified intra-testicular deficit of $\mathrm{E}_{2}$ levels associated to inefficient histone removal and studied the molecular mechanism of histone displacement by taking into account histone $\mathrm{H} 4$ acetylation.

In particular, using WT and CB1 ${ }^{--}$mice, we analyzed the gene expression of $\mathrm{Cdyl}$ and $\mathrm{Brdt}$, as a significant player in histone removal, and analyzed the histone H4tetraAc levels, as a main signal of histone displacement [8]. Histone $\mathrm{H} 3$ was used for monitoring efficiency of histone displacement and normalized histone H4tetraAc levels. We excluded analysis of $\mathrm{CB} 1^{+/-}$mice as a sperm phenotype of these animals, at molecular and biochemical levels, including histone retention, is very similar to that of WT mice [33,38].

Results demonstrate that $\mathrm{E}_{2}$ were significantly $(p<0.01)$ lower in $\mathrm{CB}^{---}(0.73 \pm 0.043 \mathrm{pg} / \mathrm{mg})$ than in WT $(1.24 \pm 0.049 \mathrm{pg} / \mathrm{mg})$ testis (Figure 4$)$, which revealed $\sim 40 \%$ of $\mathrm{E}_{2}$ reduction. 


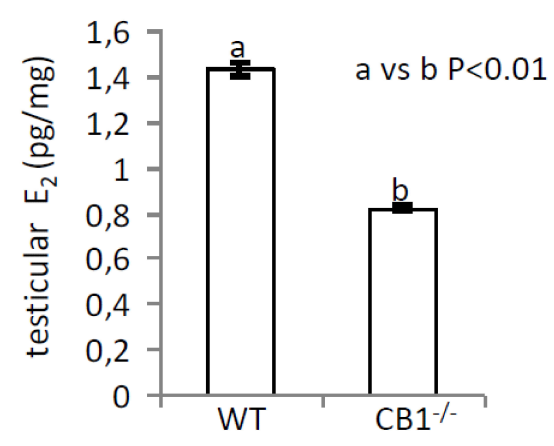

Figure 4. $\mathrm{E}_{2}$ levels in testis from $\mathrm{WT}$ and $\mathrm{CB}^{-/-}$mice by EIA assay. Values were expressed in pg for $\mathrm{mg}$ of tissue $(\mathrm{pg} / \mathrm{mg})$ and reported as mean values \pm S.E.M. Graph was representative of three testis from six different animals/genotype ( $n=6$ animals for each genotype in triplicates) (a vs. $\mathrm{b} p<0.01$ ).

Gene expression analysis of $C d y l$ and Brdt showed no significant differences, WT vs. $\mathrm{CB}^{-1}$ (Figure 5A), while significant variation was observed when we analyzed histone $\mathrm{H} 3$ and H4tetraAc levels. Quantitative densitometry analysis of signals showed a significantly higher histone $\mathrm{H} 3$ content in $\mathrm{CB}^{-/-}$than in WT mice both in testis $(p<0.01)$ and in caput SPZ $(p<0.05)$. Relatively to total histone content, histone H4tetraAc was higher in WT compared to CB1 ${ }^{-/-}$testis (Figure $5 \mathrm{~B}, \mathrm{C}$ ).

A)
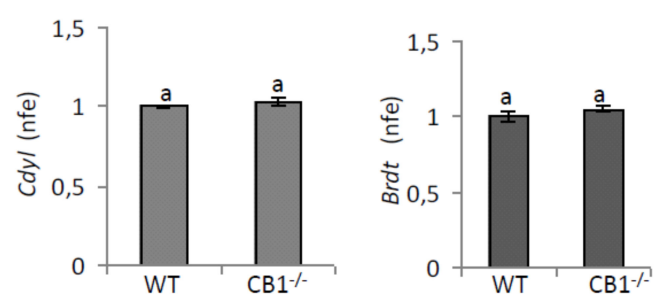

B)
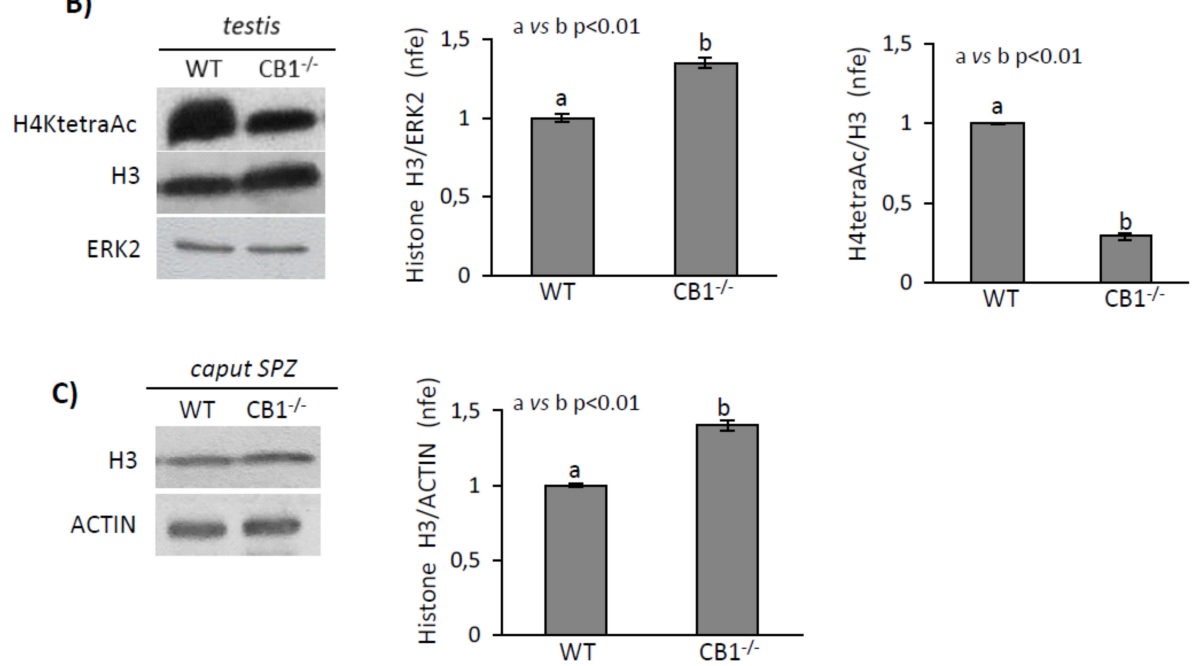

Figure 5. RTqPCR analysis of $C d y l$ and $B r d t$ in testis of WT and $C B 1^{-/-}$mice (A). Transcript amounts was reported as normalized fold expression (nfe) relatively to Rps18 gene. Western blot analysis of (B) Histone H4tetraAc and Histone $\mathrm{H} 3$ in testis and (C) Histone H3 in caput SPZ of WT and CB1 ${ }^{-/}$ mice. H4tetraAc and $\mathrm{H} 3$ amount was quantified by densitometry analysis, normalized against ERK2 (for testis) or ACTIN (for caput SPZ) signals and expressed as a fold change of OD values. All data are reported as mean values \pm S.E.M. Graphs were representative of six or seven testis from six/seven different animals/genotype ( $n=6$ or 7 animals for each genotype in triplicates). Different letters indicated statistical significance $(p<0.05$ or $p<0.01)$. 


\section{Material and Methods}

\subsection{Experimental Animals}

CB1-wild-type $\left(\mathrm{CB}^{+/+}\right.$or WT) male mice or males carrying a CB1 null mutation [41] either under heterozygous $\left(\mathrm{CB}^{+/-}\right)$or homozygous $\left(\mathrm{CB}^{--}\right)$conditions were used in this study. Heterozygous mice were bred on a CD1 background (Charles River Laboratory, Lecco, Italy) before generating male mice $\left(\mathrm{WT}, \mathrm{CB} 1^{+-}, \mathrm{CB}^{-/-}\right)$.

The number of the enrolled adult animals was determined by the parameters that we have to adopt for the $G^{*}$ Power analysis required to get the permission for in vivo experiments in Italy, which is suggested by the Legal Entity giving the permission.

All animals were maintained on a standard pellet diet with free access to water. Adult males (4-8 months) were killed by $\mathrm{CO}_{2}$ asphyxia and testes and/or epididymis were processed depending on the experimental procedure, as previously described [38]. In detail, testes were rapidly removed and properly stored at $-80^{\circ} \mathrm{C}$, while epididymis were dissected and used to collect SPZs from caput (caput SPZ) and cauda (cauda SPZ) regions, as described below.

Experiments were approved by the Italian Ministry of Education and the Italian Ministry of Health with authorization $n^{\circ} 941 / 2016-P R$ issued on 10.10.2016. Procedure involving animal care were carried out in accordance with the National Research Council's publication Guide for Care and Use of Laboratory Animals (National of Institutes of Health Guide).

\subsection{In Vivo Experiment with 17- $\beta$ Estadiol $\left(E_{2}\right)$}

$\mathrm{CB}^{-/-}$male mice $(n=11)$ of 24 days postpartum $(d p p)$ were injected with physiological solution containing vehicle ( $1 \%$ ethanol, $n=3$ animals), $\mathrm{E}_{2}\left(1.5 \mu \mathrm{g} / 100 \mathrm{~g}\right.$ dose for each injection, $n=4$ animals), $\mathrm{E}_{2}$ $(1.5 \mu \mathrm{g} / 100 \mathrm{~g}$ dose for each injection) in combination with the estrogen receptor (ER) antagonist ICI182780 (ICI, $15 \mu \mathrm{g} / 100 \mathrm{~g}$ dose for each injection, $n=4$ animals for $\mathrm{E}_{2}+\mathrm{ICI}$ group). We decided to avoid the anti-estrogen alone from analysis due to its effect on testis, efferent ductile, and epididymis [42]. All the substances were dissolved in ethanol, diluted in $100 \mu \mathrm{L}$ physiological solution (each injection/dose contained $1 \%$ ethanol), and injected intraperitoneally on alternate days for seven weeks. Doses and time of treatment have previously been reported $[2,33]$.

In adult animals, overlapping waves of spermatogenesis continuously produce SPZs that accumulate in the cauda region of the epididymis. Therefore, in order to recover and analyze the largest and most homogeneous number of efficiently protaminated SPZs, the pharmacological treatment was performed on prepubertal animals during the first wave of spermatogenesis. Specifically, treatment was performed on $24 d p p$ mice according to the presence of round SPT and was halted seven weeks later because the first wave of spermatogenesis and sperm transit along epididymis, from caput-to-cauda, require approximately 60 days. At the end of this period, WT animals (70-days-old) and all treated animals were euthanized with $\mathrm{CO}_{2}$ and testes or epididymis ( $n=3$ or 4 for experimental group) were processed depending on the experimental procedure. In detail, testes were rapidly removed, fixed, or frozen on dry ice and properly stored for routine histological control and Western blot analysis. Epididymis were dissected and used to collect caput and cauda SPZs, as described below.

\subsection{Sperm Collection From Caput and Cauda Epididymis}

Caput and cauda epididymis (from $n=4$ mice for each genotype) were separately immersed in PBS (pH 7.6) and cut to let SPZs flow out from the ducts, as previously reported [38]. Samples of caput and cauda SPZs were then filtered throughout cheesecloth, dissolved in $1 \mathrm{ml}$ of ice-cold PBS (pH 7.4) buffer $\left(1 \times 10^{6} / 100 \mu \mathrm{L}\right)$, and centrifuged at $600 \times \mathrm{xg}$ for $5 \mathrm{~min}$. Aliquots of caput SPZ from WT and CB1 ${ }^{--}$ mice were frozen on dry ice and stored for Western blot analysis $\left(n=10 \mathrm{WT}\right.$ aliquots and $10 \mathrm{CB}^{-/-}$ aliquots from each of animals). Aliquots of caput and cauda SPZs from WT, $\mathrm{CB} 1^{+/-}$and $\mathrm{CB} 1^{-/-}$mice were properly fixed [38] and processed for AO staining $\left(n=4 \mathrm{WT}\right.$ aliquots and $4 \mathrm{CB}^{-/}$aliquots from each of animals). 


\subsection{Acridine Orange Staining Analysis}

The fluorochrome AO intercalates into double strand DNA (native DNA) as a monomer and fluoresces green. Conversely, when it binds to single strand DNA (denatured or single strand DNA) as an aggregate, a red fluorescence is observed. DNA is vulnerable to denaturation under acid conditions $[38,43]$. This metachromatic shift from green (FL1-H) to red (FL3-H) has been used to measure chromatin quality indices of caput and cauda SPZs under acid conditions [44,45]. In particular, using cytofluorimetry analyses, we evaluated the percentage of SPZs with high DNA stainability (i.e., HDS) or susceptibility of DNA to acid denaturation at strand break (i.e., DD), and thiol/disulphide status (i.e., TDS). Values were considered as spermatic indices of uncondensed chromatin (i.e., HDS, calculated as intensely green [FL1-H $>10^{3}$ ] fluorescing DNA/total fluorescing DNA [FL1-H $>10^{1}+$ FL3-H $\left.>10^{1}\right]$ ), DNA denaturation and damage (i.e., DD, calculated as red fluorescing [FL3-H $\left.>10^{1}\right] /$ total fluorescing DNA, [FL1-H $>10^{1}+$ FL3-H $>10^{1}$ ]), and thiol groups oxidation status (i.e., TDS, calculated as red fluorescing [FL3-H $>10^{1}$ ]/green fluorescing [FL1-H $\left.>10^{1}\right]$ DNA), respectively $[33,38,44,45]$.

Sperm samples were treated for $30 \mathrm{~s}$ with $400 \mu \mathrm{L}$ of a solution of $0.1 \%$ Triton X-100, $0.15 \mathrm{M} \mathrm{NaCl}$ and $0.08 \mathrm{~N} \mathrm{HCl}$, pH 1.2. After $30 \mathrm{~s}, 1.2 \mathrm{~mL}$ of staining buffer $[6 \mu \mathrm{g} / \mathrm{mL}$ AO, $37 \mathrm{mM}$ citric acid, $126 \mathrm{mM}$ $\mathrm{Na}_{2} \mathrm{HPO}_{4}, 1 \mathrm{mM}$ disodium EDTA, $0.15 \mathrm{M} \mathrm{NaCl}, \mathrm{pH}$ 6.0] was admixed to the test tube and analyzed by flow cytometry. After excitation by a $488 \mathrm{~nm}$ wavelength light source, AO bound to a double-stranded DNA fluorescent green $(515-530 \mathrm{~nm})$ and AO bound to a single-stranded DNA fluorescent red $(630 \mathrm{~nm}$ or greater). A minimum of 10,000 cells were analyzed by fluorescent activated cell sorting (FACS Calibur, BD BioScience, Milan, Italy).

\section{5. $R T-q P C R$}

Testes from WT and $\mathrm{CB}^{-/-}$mice $\left(n=6 \mathrm{WT}\right.$ testes and $7 \mathrm{CB}^{-/-}$testes $)$were homogenized in TRIZOL Reagent (Invitrogen Life Technologies, Milan, Italy) in agreement with manufacturer's instructions for total RNA extraction. RNA aliquots $(10 \mu \mathrm{g}$ ) were treated with $1 \mu$ l Deoxyribonuclease (DNAse, $10 \mathrm{U} / \mu \mathrm{l}$ ) at $37^{\circ} \mathrm{C}$ for $10 \mathrm{~min}$ and processed in agreement with manufacturer's instructions (GE Healthcare, Milan, Italy). Purity and integrity of RNA samples $\left(n=3 \mathrm{WT}\right.$ and $\left.3 \mathrm{CB1}^{--}\right)$were determined by spectrophotometry and electrophoresis. Then RNA was used for cDNA synthesis and real time-qPCR, as already reported [46]. Gene expression analysis, corrected for PCR efficiency and normalized toward a reference gene [ribosomal protein S18, Rps18 (sense: 5'-gagactctggcatgctaactag-3'; antisense: $5^{\prime}$-ggacatctaagggcatcacag- $\left.3^{\prime}\right)$ ], was performed by CFX Manager software (Bio-Rad). Normalized fold expression of mRNAs was calculated by applying the $2^{-\Delta \Delta C t}$ method.

Primer sequences for Cdyl mRNA (sense: 5'-gaaagcactaaaatggcagac-3', antisense: $5^{\prime}$-gcccaaaccacatcacaaag $-3^{\prime}$ ) and Brdt mRNA (sense: $5^{\prime}$-gattccttctgggcttcctg- $3^{\prime}$, antisense: $5^{\prime}$-gctatggaagtggtaggagtt-3') were designed through Primer3 (http://primer3.ut.ee/).

Results were expressed as a mean value of normalized fold expression (nfe) $\pm \mathrm{SEM}$.

\subsection{Western Blot Analysis}

Testes ( $n=6 \mathrm{WT}$ testes and 7 testes $\mathrm{CB}^{-/-}$) or caput SPZs ( $n=6 \mathrm{WT}$ aliquots and $7 \mathrm{CB} 1^{-/-}$aliquots), were homogenized in RIPA buffer (PBS, $\mathrm{pH} 7.4,10 \mathrm{mM}$ dithiothreitol, $0.02 \%$ sodium azide, $0.1 \%$ SDS, $1 \%$ Nonidet P-40, $0.5 \%$ sodium deoxycholate) in the presence of protease inhibitors $(10 \mu \mathrm{g} / \mathrm{mL}$ of leupeptin, aprotinin, pepstatin A, chymostatin, and $5 \mu \mathrm{g} / \mathrm{mL}$ of TPCK), as already reported [33] and analyzed by Western blot. Briefly, proteins ( $10 \mu \mathrm{g}$ for testis and $5 \mu \mathrm{g}$ for caput SPZ) were separated by SDS-PAGE (15\% acrylamide) and transferred to polyvinylidene difluoride membrane (GE Healthcare) at $280 \mathrm{~mA}$ for $2.5 \mathrm{~h}$ at $4^{\circ} \mathrm{C}$. Membrane was cut at $25 \mathrm{kDa}$ level. The upper and lower filters were treated for $3 \mathrm{~h}$ with blocking solution [5\% nonfat milk, $0.25 \%$ Tween-20 in Tris-buffered saline (TBS, pH7.6)] and then separately incubated overnight at $4^{\circ} \mathrm{C}$ in TBS-milk buffer (TBS pH 7.6, 3\% nonfat milk) with the primary antibody (Total Histone H3, diluted 1:1000, code 05-928 from Merck Millipore, Burlington, USA, ACTIN, diluited 1:5000, code E-AB-20034, Elabscience Biotechnology, Wuhan, China 
and ERK2, diluted 1:1000, code sc-1647 from Santa Cruz Biotechnology, Inc., Heidelberg, Germany, H4tetraAc diluted 1:1000, code 05-1355, from Merck Millipore, Burlington, USA). After washing in $0.25 \%$ Tween20-TBS, filters were incubated with 1:1000 horseradish peroxidase-conjugated rabbit or mouse IgG (Dako Corp., Milan, Italy) in TBS-milk buffer and then washed again. The immune complexes were detected using the enhanced chemiluminescence-Western blotting detection system (Amersham ECL Western Blotting Detection Reagent, cod: RPN2106, GE Healthcare). Signals were quantified by densitometry analysis, appropriately normalized relatively to levels of ERK1/2, ACTIN, or total H3 (post-translationally modified and unmodified H3), and graphed as a fold change of Optical Density (OD) (mean \pm S.E.M.). Since, in sperm protein extract, the ERK2 signal quickly reached saturation. To limit the error, we used ACTIN as a loading control.

Specificity of the immunoreactions was already demonstrated $[24,30,47,48]$ and, in this scenario, routinely checked by omitting the primary antibody.

\subsection{7- $\beta$ Estadiol by Enzyme Immunoassay (EIA)}

Testes from $\mathrm{WT}$ and $\mathrm{CB} 1^{--}$mice $\left(n=6 \mathrm{WT}\right.$ mice and $6 \mathrm{CB}^{--}$mice) were homogenized in $70 \%$ methanol and extracted with $2 \times 7 \mathrm{~mL}$ diethyl ether. After drying, each extract $\left(n=6 \mathrm{WT}\right.$ and $\left.6 \mathrm{CB}^{-{ }^{-}}\right)$ was dissolved in phosphate buffered saline (PBS $0.1 \mathrm{M}, \mathrm{pH}$ 7) containing $0.2 \%$ gelatine and used for $\mathrm{E}_{2}$ determination [49].

Intra-testicular $\mathrm{E}_{2}$ levels were quantified using a commercially available Enzyme Immunoassay (EIA) kit, according to the manufacturer's instructions (Cayman, Florence, Italy). The kit was a competitive assay recommended for quantification of $\mathrm{E}_{2}$ from tissue with a detection limit of approximately $20 \mathrm{pg} / \mathrm{mL}$. Different concentrations of $\mathrm{E}_{2}$ (Sigma-Aldrich) were used to verify sensibility of the assay. The intra-assay and inter-assay coefficient of variation have been determined at multiple points on a standard curve resulting as $7.9 \%$ and $5.3 \%$, respectively. Each extract $(n=6$ WT extracts and $n=6 \mathrm{CB}^{-/}$extracts from different animals) was analyzed in triplicate and values were expressed in $\mathrm{pg}$ for $\mathrm{mg}$ of tissue $(\mathrm{pg} / \mathrm{mg})$ and graphed as mean \pm S.E.M.

\subsection{Correlation Analysis}

All the HDS and TDS values relative to caput and cauda SPZ of $\mathrm{WT}, \mathrm{CB} 1^{+/}$, and $\mathrm{CB} 1^{-/-}$mice have been correlated with each other. Specifically, we included in our analysis both caput and cauda SPZ without considering the genotype and epididymal region. Data have been compared using the Excel built-in distribution functions available in Microsoft Office. The value of $r$ was considered to establish the test significance. The range $-1 \leq \mathrm{r} \leq 1$ established a negative or positive correlation between HDS and TDS.

\subsection{Data Presentation and Statistical Analysis}

ANOVA followed by Duncan's test (for a multi-group comparison) or Student's t-test (for two independent group comparisons) were conducted to identify groups with a different mean. Data were expressed as the mean \pm S.E.M. from at least three independent animals for each genotype or experimental group. For RTqPCR and Western blot analyses, triplicates from 4-7 animals/genotypes or experimental groups were considered.

\section{Discussion}

The chromatin condensation extent of mature SPZs is mainly orchestrated by testicular and epididymal events that involve chromatin remodeling mechanisms such as histone displacement/protamination and inter/intra-protamine disulphide bonds formation, respectively.

Recently, we studied the impact of $C B 1$ deletion on histone displacement by comparing histone retention and chromatin condensation of SPZs isolated from caput epididymis of $\mathrm{WT}, \mathrm{CB} 1^{+/}$, and $\mathrm{CB}^{-/}$ mice $[2,33,34,38]$. In this case, we extend our previous findings and studied the impact of CB1 deletion on the epididymal event that underlies chromatin packaging of SPZs transiting along epididymis, 
by comparing chromatin condensation indices of SPZs isolated from caput and cauda epididymis of $\mathrm{WT}, \mathrm{CB}^{+/-}$, and $\mathrm{CB}^{-/-}$mice. Specifically, the percentage of SPZs with high DNA stainability (i.e., HDS) and thiol/disulphide status (i.e., TDS) were evaluated in sperm samples collected from caput and cauda of epididymis. Values were considered as spermatic indices of uncondensed chromatin and thiol groups' oxidation status (i.e., disulphide brides formation), respectively. DNA damage is strongly related to uncondensed chromatin. Therefore, we also analyzed the susceptibility of DNA to acid denaturation at a strand break, which is considered as spermatic indices of DNA denaturation and damage (i.e., DD). However, the need of the present study was also to fulfill some gaps of knowledge about the neuroendocrine role of CB1 in the histone displacement mechanism. Therefore, using WT and $\mathrm{CB}^{-/-}$mice, we characterized the intra-testicular deficit of $\mathrm{E}_{2}$ levels associated with inefficient histone removal and also studied the molecular mechanism of histone displacement.

Our results suggest that CB1 activity preserved the chromatin condensation status of SPZ transiting along the epididymis $[2,33,34,38]$. Indeed, the comparative analysis of sperm samples collected from caput and cauda epididymis of WT and $\mathrm{CB}^{+/-}$mice revealed scanty HDS values, with no significant difference caput vs. cauda. Such a phenotype was reasonably ascribable to the efficiency of the DNA protamination process occurring during spermiogenesis since protamine-based structures are reported to highly condense chromatin of SPZs. Either WT or $\mathrm{CB}^{+/-}$mice mostly produce efficiently protaminated SPZs with a physiological content of histone proteins [38]. However, the comparative analysis of sperm samples collected from caput and cauda epididymis of $\mathrm{CB}^{-/-}$mice showed HDS values were significantly high compared to $\mathrm{WT}$ and $\mathrm{CB} 1^{+/}$mice both in caput and cauda, with a significant increase from caput-to-cauda, which suggests that CB1 gene deletion, besides increasing the production of poorly condensed SPZs in caput epididymis [38], also interfered with sperm chromatin maturation during epididymal transit. The observed susceptibility of chromatin to swelling detected in SPZs transiting from caput-to-cauda suggested that CB1 deletion, more than poorly protaminated DNA, negatively affected the sperm chromatin condensation status during the epididymal transit. Data on the susceptibility of DNA to acid denaturation and thiol-disulphide status confirmed our hypothesis and revealed a new effect of CB1 deletion on epididymal maturation of SPZs.

In caput and cauda epididymis, sperm cells showed DD values are significantly higher in $\mathrm{CB}^{-/-}$ mice than in WT and CB1 ${ }^{+/}$. However, DD values decreased from caput to cauda epididymis, both in $\mathrm{WT}$ and $\mathrm{CB} 1^{+/-}$mice, while comparable DD values were observed in caput and cauda epididymis of $\mathrm{CB}^{-/-}$mice, which indicates genotype-dependent effects on DNA denaturation and damage of SPZs transiting along the epididymis [38]. Using the alkaline Comet assay as a highly sensitive test to reveal the percentage of damaged DNA, at a single and a double strand, we previously demonstrated that DNA damage increased in mouse SPZ transiting from caput to cauda [38]. This occurred independently by genotype, and, at a smaller extent, in WT and $\mathrm{CB}^{+/-}$compared to $\mathrm{CB} 1^{-/}$. However, DD values used as the index of DNA denaturation and damage in this scenario specifically measure susceptibility of DNA to acid denaturation at sites of DNA strand breaks [50]. When disulphide bridges-rich protamines condenses chromatin, the DNA molecule is resistant to acid denaturation since disulphide bridges counteract DNA melting [51]. Consequentially, in cauda epididymis more than in caput, the observed DD values likely reflected the protamine thiol oxidation, which is lower in SPZs of CB1-- than WT and $\mathrm{CB}^{+/-}$mice. Accordingly, TDS decreased in SPZs transiting from caput-to-cauda epididymis both in WT and $\mathrm{CB}^{+/-}$mice, while, in $\mathrm{CB}^{-/-}$mice, it was stably elevated in SPZs transiting from caput to cauda. This suggests that CB1 gene deletion interfered with thiol oxidation. However, disulphide bridges' formation in sperm cells is not exclusively restricted to protamines. Several events related to sperm maturation (e.g., progressive motility acquisition, fertilizing ability) require thiol oxidation of sperm proteins [52]. To confirm that the TDS values observed in caput and cauda SPZs of WT, $\mathrm{CB} 1^{+-}$and $\mathrm{CB}^{-/}$mice were ascribable to protamines, we carried out correlation analysis between TDS and HDS values, independently, by genotype and the epididymal region. The correlative analysis confirmed that thiol groups oxidation was significantly and directly associated to condensation of protamine-based chromatin indicating that the observed TDS values were related to protamines more than other 
proteins. DNA denaturation and chromatin de-condensation of SPZs can be originated by abnormal protaminization and/or by anomalies in the epididymal maturation. To corroborate the emerging idea that the observed susceptibility of chromatin to swelling detected in SPZs transiting along epididymis of $\mathrm{CB}^{-/-}$mice was related to an interfering effect of $\mathrm{CB1}$ deletion on disulphide bridges formation more than abnormal protaminization, we used $\mathrm{E}_{2}$ treatment as an experimental approach useful for recovery sperm protamination efficiency in CB1-null mice and verify the impact of CB1 deletion on chromatin maturation of efficiently-protamined CB1-null SPZs during the epididymal transit.

The experimental control confirmed $\mathrm{E}_{2}$-treatment efficiency. The abnormal histone retention observed in $\mathrm{CB}^{-/}$testis was responsive to treatment as $\mathrm{E}_{2}$ restored testicular content of histone $\mathrm{H} 3$ to WT values. This rescue activity on histone displacement was sufficient to predispose release in caput epididymis of efficiently protamined and condensed SPZs, which includes HDS and TDS values comparable in caput SPZs from WT mice and $\mathrm{E}_{2}$-treated mice. This also confirms previous results [38]. However, in all the experimental groups, SPZs showed high HDS and TDS values, in both caput and cauda epididymis. While HDS values significantly increased from caput to cauda, TDS values remained stably elevated. This was observed independently of treatment and in agreement with the genotype of treated animals revealing that failure of protamine thiol oxidation occurred, which was in agreement with CB1-gene deletion more than sperm protamine content. Likely, the observed recovery of histone displacement and sperm histone/protamine content was not sufficient to limit chromatin swelling during the epididymal transit in the absence of CB1. We concluded that inter/intra-protamine disulphide bonds formation is responsive to CB1. We are not able to assert that CB1 locally modulates epididymal sperm maturation. However, our data reveal CB1 involvement in packaging of sperm chromatin during the epididymal transit. Mouse and human SPZs express CB1 and produce endocannabinoids [24] and, more remarkably, a recent study carried out in humans describes CB1 in epididymal cells [53]. These are all findings suggesting that CB1 may potentially affect chromatin maturation of SPZs by local action. Further analyses need to verify this aspect and assess the endocrine and/or local control exerted by CB1. The data reported above is in agreement with the previously mentioned references showing that histone displacement and inter/intra-protamine disulphide bonds formation are both responsive to CB1.

To fulfill some gaps of knowledge about the neuroendocrine role of $\mathrm{CB} 1$ in the histone displacement event, using WT and $\mathrm{CB}^{-/}$mice, we characterized the intra-testicular deficit of $\mathrm{E}_{2}$ levels [33] and molecular mechanism associated to abnormal histone retention. In particular, we analyzed gene expression of key modulators such as Brdt and $C d y l[10,11]$, and levels of histone H4tetraAc levels as the main signal of displacement.

In agreement with aromatase expression and physiological levels of testicular $\mathrm{E}_{2}[33,54]$, results showed that $\mathrm{CB} 1$ gene deletion reduced intra-testicular estrogens levels. $\mathrm{E}_{2}$ levels decreased by $\sim 40 \%$ in $\mathrm{CB}^{-\%}$ vs. WT testis. Such a decrease was sufficient to affect histone removal since histone $\mathrm{H} 3$ content was higher in $\mathrm{CB}^{-/-}$mice compared to WT both in testis and SPZs. This abnormal histone H3 retention was associated with no change of gene expression of $B r d t$ or $C d y l$ while H4tetraAc decreased significantly in $\mathrm{CB}^{-/-}$compared to WT demonstrating that $C B 1$ deletion affected histone displacement by interfering with hyperacetylation of histone $\mathrm{H} 4$. It is easy to speculate that $40 \%$ of $\mathrm{E}_{2}$ reduction was sufficient to interfere with the histone mark of displacement, predisposing the abnormal histones retention in both testis and SPZs. Although several studies report findings about the role of $E_{2}$ in SPT differentiation [2], no information is available about the intra-testicular $E_{2}$ levels accountable for inefficiency of histone displacement.

In conclusion, our results show that CB1, via paracrine and/or endocrine cell-to-cell signaling, modulates chromatin remodeling mechanisms that orchestrate nuclear condensation extent of mature SPZs. We show that CB1-gene deletion affects the epididymal phase of chromatin condensation by interfering with inter-/intra-protamine disulphide bridges formation. In addition, it deranges efficiency of histone removal by reducing the hyperacetylation of histone $\mathrm{H} 4$. 
Our results reveal a novel and important role for $\mathrm{CB} 1 \mathrm{in}$ sperm chromatin condensation mechanisms. Any interference with CB1 activity, including the marijuana consumption, might interfere with a sperm chromatin maturation status with potentially damaging effects on sperm quality.

Author Contributions: Conceptualization, G.C. and T.C. Methodology, T.C. and L.A. Validation, G.C. and T.C. Data Curation, T.C. and F.M. Writing-Original Draft Preparation, T.C., G.C., and V.P. Writing-Review \& Editing, T.C. and G.C. Supervision, G.C., R.P., and S.F. Project Administration, G.C. Funding Acquisition, R.P. and G.C. All authors have read and agreed to the published version of the manuscript.

Funding: This research was funded by the Italian Ministry of University and Research (Grant PRIN to R. Pierantoni 2017), Università degli Studi della Campania (Grant Dip. Medicina Sperimentale-2017 to G. Cobellis), Università degli Studi della Campania (Grant VALERE, Vanvitelli per la Ricerca 2019 to G. Cobellis).

Conflicts of Interest: The authors declare no conflict of interest.

\section{References}

1. Hess, R.A. Spermatogenesis: An overview. In Encyclopedia of Reproduction; Knobil, E., Neill, J.D., Eds.; Academic Press: New York, NY, USA, 1999; pp. 539-545.

2. Cacciola, G.; Chioccarelli, T.; Fasano, S.; Pierantoni, R.; Cobellis, G. Estrogens and Spermiogenesis: New Insights from Type 1 Cannabinoid Receptor Knockout Mice. Int. J. Endocrinol. 2013, 2013, 501350. [CrossRef] [PubMed]

3. Oliva, R.; Dixon, G.H. Vertebrate protamine genes and the histone-to-protamine replacement reaction. Prog. Nucleic Acid Res. Mol. Biol. 1991, 40, 25-94. [PubMed]

4. Marcon, L.; Boissonneault, G. Transient DNA strand breaks during mouse and human spermiogenesis: New insights in stage specificity and link to chromatin remodeling. Biol. Reprod. 2004, 70, 910-918. [CrossRef] [PubMed]

5. Rousseaux, S.; Caron, C.; Govin, J.; Lestrat, C.; Faure, A.K.; Khochbin, S. Establishment of male-specific epigenetic information. Gene 2005, 345, 139-153. [CrossRef] [PubMed]

6. Oliva, R.; Castillo, J. Proteomics and the genetics of sperm chromatin condensation. Asian J. Androl. 2011, 13, 24-30. [CrossRef]

7. Battista, N.; Meccariello, R.; Cobellis, G.; Fasano, S.; Di Tommaso, M.; Pirazzi, V.; Konje, J.C.; Pierantoni, R.; Maccarrone, $\mathrm{M}$. The role of endocannabinoids in gonadal function and fertility along the evolutionary axis. Mol. Cell. Endocrinol. 2012, 355, 1-14. [CrossRef] [PubMed]

8. Chioccarelli, T.; Pierantoni, R.; Manfrevola, F.; Porreca, V.; Fasano, S.; Chianese, R.; Cobellis, G. Histone post-translational modifications and circRNAs in mouse and human spermatozoa: Potential epigenetic marks to assess human sperm quality. J. Clin. Med. 2020, 9, E640. [CrossRef]

9. Goudarzi, A.; Zhang, D.; Huang, H.; Barral, S.; Kwon, O.K.; Qi, S.; Tang, Z.; Buchou, T.; Vitte, A.L.; He, T.; et al. Dynamic competing histone $\mathrm{H} 4 \mathrm{~K} 5 \mathrm{~K} 8$ acetylation and butyrylation are hallmarks of highly active gene promoters. Mol. Cell 2016, 62, 169-180. [CrossRef]

10. Liu, S.; Yu, H.; Liu, Y.; Liu, X.; Zhang, Y.; Bu, C.; Yuan, S.; Chen, Z.; Xie, G.; Li, W.; et al. Chromodomain protein CDYL acts as a crotonyl-CoA hydratase to regulate histone crotonylation and spermatogenesis. Mol. Cell 2017, 67, 853-866. [CrossRef]

11. Flynn, E.M.; Huang, O.W.; Poy, F.; Oppikofer, M.; Bellon, S.F.; Tang, Y.; Cochran, A.G. A Subset of Human Bromodomains Recognizes Butyryllysine and Crotonyllysine Histone Peptide Modifications. Structure 2015, 23, 1801-1814. [CrossRef]

12. Li, Y.; Sabari, B.R.; Panchenko, T.; Wen, H.; Zhao, D.; Guan, H.; Wan, L.; Huang, H.; Tang, Z.; Zhao, Y.; et al. Molecular Coupling of Histone Crotonylation and Active Transcription by AF9 YEATS Domain. Mol. Cell 2016, 62, 181-193. [CrossRef] [PubMed]

13. Pittoggi, C.; Renzi, L.; Zaccagnini, G.; Cimini, D.; Degrassi, F.; Giordano, R.; Magnano, A.R.; Lorenzini, R.; Lavia, P.; Spadafora, C. A fraction of mouse sperm chromatin is organized in nucleosomal hypersensitive domains enriched in retroposon DNA. J. Cell Sci. 1999, 112, 3537-3548. [PubMed]

14. Churikov, D.; Zalenskaya, I.A.; Zalensky, A.O. Male germline-specific histones in mouse and man. Cytogenet. Genome Res. 2004, 105, 203-214. [CrossRef] [PubMed]

15. Oliva, R. Protamines and male infertility. Hum. Reprod. Update 2006, 12, 417-435. 
16. Carrell, D.T.; Emery, B.R.; Hammoud, S. Altered protamine expression and diminished spermatogenesis: What is the link? Hum. Reprod. Update 2007, 13, 313-327.

17. Soler, C.; Yeung, C.H.; Cooper, T.G. Development of sperm motility patterns in the murine epididymis. Int. J. Androl. 1994, 17, 271-278. [CrossRef]

18. Balhorn, R.; Corzett, M.; Mazrimas, J.A. Formation of intraprotamine disulfides in vitro. Arch. Biochem. Biophys. 1992, 296, 384-393. [CrossRef]

19. Rathke, C.; Baarends, W.M.; Awe, S.; Renkawitz-Pohl, R. Chromatin dynamics during spermiogenesis. Biochim. Biophys. Acta 2014, 1839, 155-168. [CrossRef]

20. Stiavnicka, M.; Alvarez, O.G.; Nevoral, J.; Králíčková, M.; Sutovsky, P. Key features of genomic imprinting during mammalian spermatogenesis: Perspectives for human assisted reproductive therapy: A review. Anat. Physiol. 2016, 6, 236. [CrossRef]

21. Bianchi, P.G.; Manicardi, G.C.; Bizzaro, D.; Bianchi, U.; Sakkas, D. Effect of deoxyribonucleic acid protamination on fluorochrome staining and in situ nick-translation of murine and human mature spermatozoa. Biol. Reprod. 1993, 49, 1083-1088. [CrossRef]

22. Bovolin, P.; Cottone, E.; Pomatto, V.; Fasano, S.; Pierantoni, R.; Cobellis, G.; Meccariello, R. Endocannabinoids are Involved in Male Vertebrate Reproduction: Regulatory Mechanisms at Central and Gonadal Level. Front. Endocrinol. 2014, 5, 54. [CrossRef] [PubMed]

23. Migliaccio, M.; Ricci, G.; Suglia, A.; Manfrevola, F.; Mackie, K.; Fasano, S.; Pierantoni, R.; Chioccarelli, T.; Cobellis, G. Analysis of Endocannabinoid System in Rat Testis During the First Spermatogenetic Wave. Front. Endocrinol. 2018, 9, 269. [CrossRef] [PubMed]

24. Cobellis, G.; Ricci, G.; Cacciola, G.; Orlando, P.; Petrosino, S.; Cascio, M.G.; Bisogno, T.; De Petrocellis, L.; Chioccarelli, T.; Altucci, L.; et al. A gradient of 2-arachidonoylglycerol regulates mouse epididymal sperm cell start-up. Biol. Reprod. 2010, 82, 451-458. [CrossRef] [PubMed]

25. Wenger, T.; Ledent, C.; Csernus, V.; Gerendai, I. The central cannabinoid receptor inactivation suppresses endocrine reproductive functions. Biochem. Biophys. Res. Commun. 2001, 284, 363-368. [CrossRef] [PubMed]

26. Maccarrone, M.; Cecconi, S.; Rossi, G.; Battista, N.; Pauselli, R.V.; Finazzi-Agro, A. Anandamide activity and degradation are regulated by early postnatal aging and follicle-stimulating hormone in mouse Sertoli cells. Endocrinology 2003, 144, 20-28. [CrossRef]

27. Maccarrone, M.; Barboni, B.; Paradisi, A.; Bernabò, N.; Gasperi, V.; Pistilli, M.G.; Fezza, F.; Lucidi, P.; Mattioli, M. Characterization of the endocannabinoid system in boar spermatozoa and implications for sperm capacitation and acrosome reaction. J. Cell Sci. 2005, 118, 4393-4404. [CrossRef]

28. Rossato, M.; Ion Popa, F.; Ferigo, M.; Clari, G.; Foresta, C. Human sperm express cannabinoid receptor Cb1, the activation of which inhibits motility, acrosome reaction, and mitochondrial function. J. Clin. Endocrinol. Metab. 2005, 90, 984-991. [CrossRef]

29. Cobellis, G.; Cacciola, G.; Scarpa, D.; Meccariello, R.; Chianese, R.; Franzoni, M.F.; Mackie, K.; Pierantoni, R.; Fasano, S. Endocannabinoid system in frog and rodent testis: Type-1 cannabinoid receptor and fatty acid amide hydrolase activity in male germ cells. Biol. Reprod. 2006, 75, 82-89. [CrossRef]

30. Cacciola, G.; Chioccarelli, T.; Mackie, K.; Meccariello, R.; Ledent, C.; Fasano, S.; Pierantoni, R.; Cobellis, G. Expression of type-1 cannabinoid receptor during rat postnatal testicular development: Possible involvement in adult leydig cell differentiation. Biol. Reprod. 2008, 79, 758-765. [CrossRef]

31. Grimaldi, P.; Orlando, P.; Di Siena, S.; Lolicato, F.; Petrosino, S.; Bisogno, T.; Geremia, R.; De Petrocellis, L.; Di Marzo, V. The endocannabinoid system and pivotal role of the CB2 receptor in mouse spermatogenesis. Proc. Natl. Acad. Sci. USA 2009, 106, 11131-11136. [CrossRef]

32. Chianese, R.; Ciaramella, V.; Scarpa, D.; Fasano, S.; Pierantoni, R.; Meccariello, R. Anandamide regulates the expression of GnRH1, GnRH2, and GnRH-Rs in frog testis. Am. J. Physiol. 2012, 303, E475-E487. [CrossRef] [PubMed]

33. Cacciola, G.; Chioccarelli, T.; Altucci, L.; Ledent, C.; Mason, J.I.; Fasano, S.; Pierantoni, R.; Cobellis, G. Low 17beta-estradiol levels in Cnr1 knock-out mice affect spermatid chromatin remodeling by interfering with chromatin reorganization. Biol. Reprod. 2013, 88, 1-12. [CrossRef] [PubMed]

34. Cacciola, G.; Chioccarelli, T.; Altucci, L.; Viggiano, A.; Fasano, S.; Pierantoni, R.; Cobellis, G. Nuclear size as estrogen-responsive chromatin quality parameter of mouse spermatozoa. Gen. Comp. Endocrinol. 2013, 193, 201-209. [CrossRef] [PubMed] 
35. Cobellis, G.; Meccariello, R.; Chianese, R.; Chioccarelli, T.; Fasano, S.; Pierantoni, R. Effects of Neuroendocrine CB1 Activity on Adult Leydig Cells. Front. Endocrinol. 2016, 7, 47. [CrossRef]

36. Pierantoni, R.; Cobellis, G.; Meccariello, R.; Cacciola, G.; Chianese, R.; Chioccarelli, T.; Fasano, S. CB1 activity in male reproduction: Mammalian and nonmammalian animal models. Vitam. Horm. 2009, 81, 367-387.

37. Meccariello, R.; Chianese, R.; Chioccarelli, T.; Ciaramella, V.; Fasano, S.; Pierantoni, R.; Cobellis, G. Intra-testicular signals regulate germ cell progression and production of qualitatively mature spermatozoa in vertebrates. Front. Endocrinol. 2014, 5, 69. [CrossRef]

38. Chioccarelli, T.; Cacciola, G.; Altucci, L.; Lewis, S.E.; Simon, L.; Ricci, G.; Ledent, C.; Meccariello, R.; Fasano, S.; Pierantoni, R.; et al. Cannabinoid receptor 1 influences chromatin remodeling in mouse spermatids by affecting content of transition protein 2 mRNA and histone displacement. Endocrinology 2010, 151, 5017-5029. [CrossRef]

39. Ricci, G.; Cacciola, G.; Altucci, L.; Meccariello, R.; Pierantoni, R.; Fasano, S.; Cobellis, G. Endocannabinoid control of sperm motility: The role of epididymus. Gen. Comp. Endocrinol. 2007, 153, 320-322. [CrossRef]

40. Francavilla, F.; Battista, N.; Barbonetti, A.; Vassallo, M.R.; Rapino, C.; Antonangelo, C.; Pasquariello, N.; Catanzaro, G.; Barboni, B.; Maccarrone, M. Characterization of the endocannabinoid system in human spermatozoa and involvement of transient receptor potential vanilloid 1 receptor in their fertilizing ability. Endocrinology 2009, 150, 4692-4700. [CrossRef]

41. Ledent, C.; Valverde, O.; Cossu, G.; Petitet, F.; Aubert, J.F.; Beslot, F.; Bohme, G.A.; Imperato, A.; Pedrazzini, T.; Roques, B.P.; et al. Unresponsiveness to cannabinoids and reduced addictive effects of opiates in CB1 receptor knockout mice. Science 1999, 283, 401-404. [CrossRef]

42. Oliveira, C.A.; Zhou, Q.; Carnes, K.; Nie, R.; Kuehl, D.E.; Jackson, G.L.; Franca, L.R.; Nakai, M.; Hess, R.A. ER function in the adult male rat: Short-And long-term effects of the antiestrogen ICI 182,780 on the testis and efferent ductules, without changes in testosterone. Endocrinology 2002, 143, 2399-2409. [CrossRef] [PubMed]

43. Evenson, D.P.; Jost, L.K.; Marshall, D.; Zinaman, M.J.; Clegg, E.; Purvis, K.; de Angelis, P.; Claussen, O.P. Utility of sperm chromatin structure assay as a diagnostic tool in the human fertility clinic. Hum. Reprod. 1999, 14, 1039-1049. [CrossRef] [PubMed]

44. Evenson, D.P.; Larson, K.L.; Jost, L.K. Sperm chromatin structure assay: Its clinical use for detecting sperm DNA fragmentation in male infertility and comparisons with other techniques. J. Androl. 2002, 23, $25-43$. [CrossRef] [PubMed]

45. Said, S.; Funahashi, H.; Niwa, K. DNA stability and thiol-disulphide status of rat sperm nuclei during epididymal maturation and penetration of oocytes. Zygote 1999, 7, 249-254. [CrossRef]

46. Suglia, A.; Chianese, R.; Migliaccio, M.; Ambrosino, C.; Fasano, S.; Pierantoni, R.; Cobellis, G.; Chioccarelli, T. Bisphenol A induces hypothalamic down-regulation of the the cannabinoid receptor 1 and anorexigenic effects in male mice. Pharmacol. Res. 2016, 113, 376-383. [CrossRef]

47. Acone, G.; Trabucco, E.; Colacurci, N.; Cobellis, L.; Mackie, K.; Meccariello, R.; Cacciola, G.; Chioccarelli, T.; Fasano, S.; Pierantoni, R.; et al. Low type I cannabinoid receptor levels characterize placental villous in labouring delivery. Placenta 2009, 30, 203-205. [CrossRef]

48. Trabucco, E.; Acone, G.; Marenna, A.; Pierantoni, R.; Cacciola, G.; Chioccarelli, T.; Mackie, K.; Fasano, S.; Colacurci, N.; Meccariello, R.; et al. Endocannabinoid system in first trimester placenta: Low FAAH and high CB1 expression characterize spontaneous miscarriage. Placenta 2009, 30, 516-522. [CrossRef]

49. Pierantoni, R.; Iela, L.; d'Istria, M.; Fasano, S.; Rastogi, R.K.; Delrio, G. Seasonal testosterone profile and testicular responsiveness to pituitary factors and gonadotrophin releasing hormone during two different phases of the sexual cycle of the frog (Rana esculenta). J. Endocrinol. 1984, 102, 387-392. [CrossRef]

50. Evenson, D.P. The Sperm Chromatin Structure Assay (SCSA (®)) and other sperm DNA fragmentation tests for evaluation of sperm nuclear DNA integrity as related tofertility. Anim. Reprod. Sci. 2016, 169, 56-75. [CrossRef]

51. Ward, W.S.; Coffey, D.S. DNA packaging and organization in mammalian spermatozoa: Comparison with somatic cells. Biol. Reprod. 1991, 44, 569-574. [CrossRef]

52. Seligman, J.; Newton, G.L.; Fahey, R.C.; Shalgi, R.; Kosowear, N.S. Nonprotein thiols and disulfides in rat epididymal spermatozoa and epididymal fluid: Role of g-Glutamyl-Transpeptidase in sperm maturation. J. Androl. 2005, 26, 629-637. [CrossRef] [PubMed] 
53. Nielsen, J.E.; Rolland, A.D.; Rajpert-De Meyts, E.; Janfelt, C.; Jørgensen, A.; Winge, S.B.; Kristensen, D.M.; Juul, A.; Chalmel, F.; Jégou, B.; et al. Characterisation and localisation of the endocannabinoid system components in the adult human testis. Sci. Rep. 2019, 9, 12866. [CrossRef] [PubMed]

54. Errico, S.; Chioccarelli, T.; Moggio, M.; Diano, N.; Cobellis, G. A New LC-MS/MS method for simultaneous and quantitative detection of bisphenol-A and steroids in target tissues: A power tool to characterize the interference of bisphenol-A exposure on steroid levels. Molecules 2019, 25, E48. [CrossRef] [PubMed]

(C) 2020 by the authors. Licensee MDPI, Basel, Switzerland. This article is an open access article distributed under the terms and conditions of the Creative Commons Attribution (CC BY) license (http://creativecommons.org/licenses/by/4.0/). 